\title{
Accuracy of concrete strength prediction behavior in simulating punching shear behavior of flat slab using finite element approach in Abaqus
}

\author{
Zainab M. R. Abdul Rasoul ${ }^{1}$, Hawra Mohamed Ali M. Taher ${ }^{2}$
}

${ }_{1,2}$ Departement of civil Engineering, University of Kerbala, 56001 Kerbala, Iraq

\begin{tabular}{ll}
\hline Article Info & ABSTRACT \\
\cline { 2 - 3 } Received Jun $12^{\text {th }}, 201 \mathrm{x}$ & $\begin{array}{l}\text { This study investigates the accuracy of prediction normal concrete behavior in } \\
\text { simulating punching shear strength of flat slab using finite element modelling } \\
\text { in Abaqus. The Eurocode and FIB standards were adopted to predict concrete } \\
\text { curves for compressive and tensile stresses, in addition to two models } \\
\text { adopted in this study based on preview expereimental stuies. Then }\end{array}$ \\
punching shear strength of two selected flat slab specimens (with and without \\
Keyword: & $\begin{array}{l}\text { studs) were simulated in Abaqus to validate punching shear force vs vertical } \\
\text { midspan displacement for the adopted experimental work. Simulation results } \\
\text { Abaqus }\end{array}$ \\
have shown very good results in comparison to the finite element analysis \\
Punching shear & (FEA) curves. Also, the test results have showed that a comparable result with \\
Concrete behavior & various codes models (ACI-318, BS-8110, EC2, and CEB FIB model code \\
Finite element simulation & $90)$.
\end{tabular}

Corresponding Author:

First Author,

Departement of civil Engineering,

Universit of Kerbala,

56001 Karbala, Iraq.

Email: zainabm@uokerbala.edu.iq

\section{Introduction}

Punching shear, or tow way shear failure, is a structural concrete failure phenomenon, in which the support (generally columns) tend to spell out the concrete and punching it. It is important in heavily loaded flat slabs. Such failure has been covered by numerous researchers in their studies. Also, most of institutions referred in codes and standers the theory of such failure, such as ACI standards in the edition ACI-318 [1], British standards in the edition BS8110 [2], Eurocode2 [3], ...ets. Punching shear failure could be occurred with slabs (flat plate slab) or footings (raft, and isolated footings) when the applied shear forces exceed the concrete nominal shear strength, see Figure (1).

Numerous researches focused their studies on such type of failure numerically and experimently.Faria et al., [4] studied numerically punching shear behavior of flat slab stand on a square column under different geometrical and materials parameters, using 3D finite element simulation utilizing form ATENA package. They concluded that the studied parameters of compressive strength, reinforcement ratio, and fracture energy have great effect on punching shear strength of the concrete. They found that concrete tensile strength property and modulus of elasticity have great effect regarding punching behavior in terms of stiffness and cracking. 


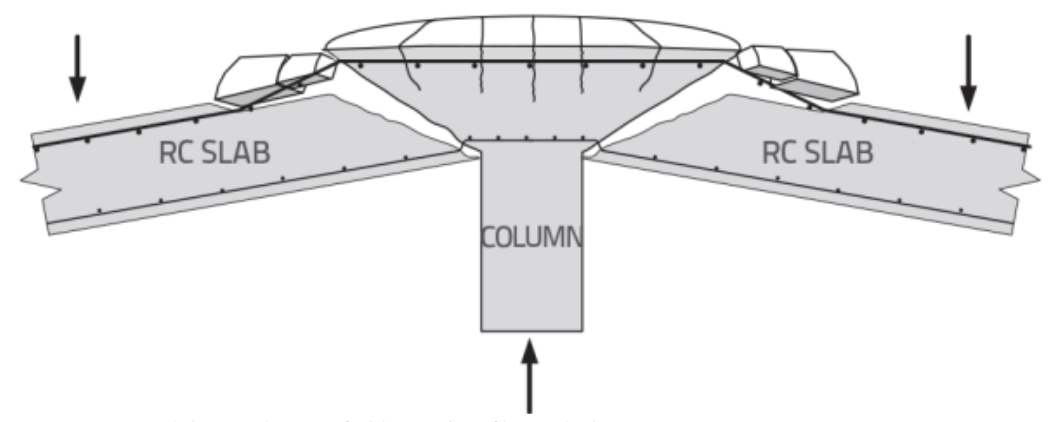

Figure 1. Punching shear failure in flat slab concrete structure (Source [5])

Ramana et al.[6]evaluated punching resistance of a square flat slab casted with $60 \mathrm{MPa}$ and $25 \mathrm{Mpa}$ compressive strength with dimensions $1100 \mathrm{~mm}$ and $50 \mathrm{~mm}$ for length and thickness, respectively. They found that high strength concrete has higher punching shear capacity by about $59 \%$ compared with normal concrete strength. They further stated that the stiffness of the new mix has much higher than normal one.

Alwash et al.[7] investigated experimentally and numerically the impact of repeated load action on the punching shear behavior of $100 \mathrm{~mm}$ thickness square reinforced concrete flat slab of dimensions $900 \mathrm{~mm}$ x900 mm. the casted specimens were performed with high strength concrete of $82 \mathrm{Mpa}$ then compared with $25 \mathrm{Mpa}$. They stated that HSC concrete specimens offers higher resistance to repeated punching load when compared with NSC. Also, it has observed that the 3D finite element simulation results were go with all aspect of the experimental specimens' results, with max average difference of $5 \%$ for all specimens. The mentioned that concrete material modeling has great effect on the results.

Ammash and Kadhim [8] investigated the punching shear behavior of normal concrete (25 MPa) square flat slab with different column capital dimensions. The dimensions of the studied slab specimens are 1600x1600 mm, and $100 \mathrm{~mm}$ slab thickness. He used Abaqus package to simulate the experimental program, and utilized form concrete damaged plasticity for modelling concrete material. They found that both experimental and numerical results showed that size and shape of columns capital have significant effect on punching shear resistance. They further stated that there was a good compatibility between the FE numerical and experimental results.

Bartolac [5] investigated punching shear resistance of flat slab without shear reinforcement. They compared the experimental work with several structural codes such as, ACI-318, Eurocode2, and FIB model code2010. They concluded that most of the design code underestimates punching shear strength of the concrete compared to the experimental results, except the Eurocode 2, which gave higher results than the experimental.

Bompa and Elghazouli [9] examined the structural response of reinforced concrete flat slabs, provided with fully embedded shear-heads, through detailed three-dimensional nonlinear numerical simulations and parametric assessments using concrete damage plasticity models.

Fernández Ruiz and Muttoni [10] examined punching shear strength of reinforced concrete flat slab enhanced with shear reinforcement. they concluded that the resistance of concrete to punching is not constant, in the contract to what mentioned in codes and standards.

Genikomsou and Polak [11] investigated performance of flat slab column connection models without reinforcement punching shear resistance, using non linear finite element simulation with Abaqus package, in addition to the experimental program. they utilized from the damage plasticity model for the concrete material. They stated that a reasonable relation between the experimental and the simulated models were observed.

Also, Genikomsou and Polak [12] simulated concrete flat slab behavior for interior column slab connection with transverse reinforcement. The experimental program then simulated with nonlinear finite 
element analysis using concrete damaged plasticity model for material modelling in Abaqus. They found a good relation between the simulated and the experimental results of the tested models. They confirmed the reliability and the ability of the examined model in the parametric studies for punching shear behavior for models with and without reinforcement.

The same researchers [13] studied experienced punching shear behavior of interior and edge concrete flat slab models under static and cyclic load using nonlinear 3D finite element in Abaqus, utilizing from the concrete damage plasticity model for concrete material. He stated that the examined numerical models can be properly predict the experimental models in term of shear response.

This study aims to predict concrete strength curves for concrete damaged plasticity in Abaqus depending on the compressive strength only, utilizing from EC2 and FIB structural codes to predict concrete stress strain response. Then the predicted properties shall be used to validate three experimental flat slab specimens, as shall be explained in next sections.

\section{Material modelling of the concrete}

It has well known that concrete has more than one phase behavior when subjected to an external force. In first trials of simulations, concrete considered as isotropic, homogenous, with linear stress strain relationship. This idea reflected a behavior far from reality. Thus, numerous researchers have focused their studies to achieve models can reflect and simulate the reality. They started to model the plastic phase of the concrete in addition to the elastic phase, to be mixed of elasto-plastic behavior.

In recent time, on the most efficient elasto-plastic model that most of researchers agreed to simulate concrete material behavior is the concrete damaged plasticity model. The CDP model assumes two failure mechanisms to predict concrete behavior, as shall be discussed in next section.

\subsection{CDP model}

Lubliner et al [14] had predicted one of the important models that has covered by Abaqus, which is called the concrete damage plasticity model. The model then modified by Lee and Fenves [15]. The CDP model is a continuum based on the theory of plasticity which assumes tow failure criteria are, the compressive crushing and tension stiffening. In general, yield surface hardening is characterized by two main parameters are, the tensile and compressive strains, as illustrated in Equation (1).

The concrete damaged plasticity model is a continuum, plasticity based, damage model for concrete behavior. The model is governed by two basic failure mechanisms, they are; compressive crushing and tensile cracking. The evolution of failure surface is governed by two major parameters are; tensile and compressive equivalent plastic strains. These two parameters are control failure mechanisms under tension and compression loadings.

The CDP model assumes that both uniaxial tensile and compressive responses are characterized by plastic damage, as can be seen in Figure (2).
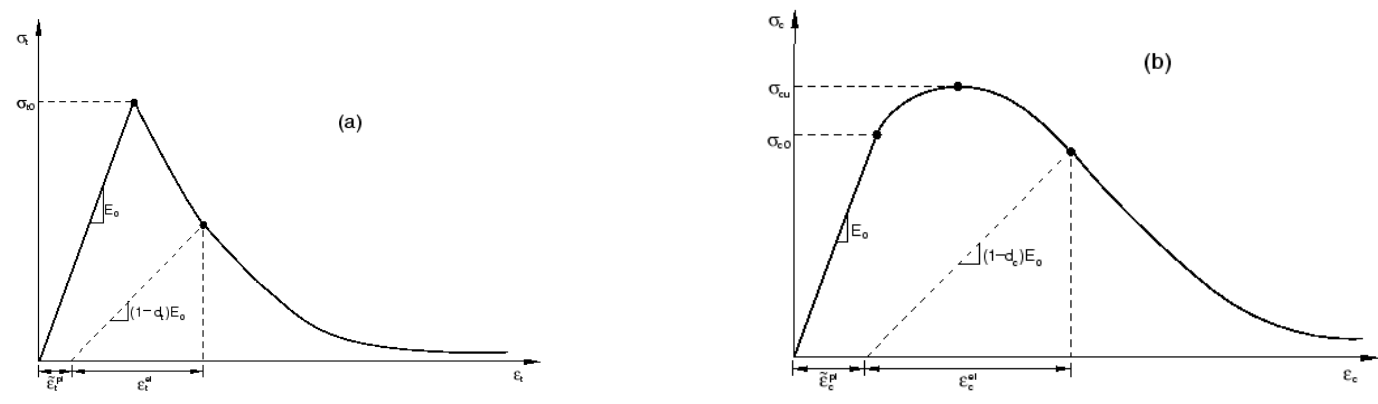

Figure 2. Response of concrete to uniaxial loading in tension (a) and compression (b). (Source [16]) 


$$
\left.F=\frac{1}{1-\alpha}+\left(\bar{q}-3 \alpha \bar{p}+\beta \bar{\epsilon}^{p l}\right)<\hat{\sigma}_{\max }>-\gamma<\hat{\sigma}_{\max }>\right)-\bar{\sigma}_{c}\left(\bar{\epsilon}_{c}^{p l}\right)
$$

$\alpha$ parameter depends on the ratio of biaxial $\left(a_{b 0}\right)$ to the uniaxial $\left(a_{c 0}\right)$ compressive strengths, which given as:

$$
\alpha=\frac{\left(a_{b 0} / a_{c 0}\right)-1}{2\left(a_{b 0} / a_{c 0}\right)-1}
$$

The parameter $\gamma$ in equation (1), is defined as the shape of surface loading, described as follows:

$$
\gamma=\frac{3\left(1-K_{c}\right)}{2 K_{c}-1}
$$

Kc parameter can be defined as the ratio of tensile to the compressive meridian, which can be expressed as the shape of failure surface in deviatory plane.

The $\bar{p}$ and $\bar{q}$ are tow parameters which defines p-q plane of failure, $\bar{q}$ represents effective stress tensor, $\bar{q}$ represents mises equivalent effective stress. Those parameters can be determined using equations $(4,5)$

$$
\begin{aligned}
& \bar{p}=-\frac{1}{3} \bar{\sigma} I_{1} \\
& \bar{q}=\sqrt{\frac{3}{2}-(\bar{s}: \bar{s})}
\end{aligned}
$$

Where $\bar{s}$ is deviatoric effective stress, and $\bar{p}$ is invariant stress tensor in fist degree, both parameters are calculated using equations $(6,7)$

$$
\begin{gathered}
I_{1}=\operatorname{trace}(\bar{\sigma}) \\
\bar{s}=\bar{\sigma}+\bar{p} I
\end{gathered}
$$

The parameters $\beta\left(\bar{\epsilon}^{p l}\right)$ can be determined as in equation (8)

$$
\begin{aligned}
& \beta\left(\bar{\epsilon}^{p l}\right)=\frac{\bar{\sigma}_{c}\left(\bar{\epsilon}_{c}^{p l}\right)}{\bar{\sigma}_{t}\left(\bar{\epsilon}_{t}^{p l}\right)}(1-\alpha)-(1+\alpha) \\
& \sigma=(1-d) \bar{\sigma}=(1-d) E_{0}:\left(\epsilon-\epsilon^{p l}\right)
\end{aligned}
$$

The damage indicator parameters $\mathrm{d}$ in the CDP model can be defined in term of tensile and compressive damage parameters, dt and dc, respectively, which calculated from equations (10)

$$
(1-d)=\left(1-s_{t} d_{c}\right)\left(1-s_{c} d_{t}\right)
$$

Both of $s_{t}$ and $s_{c}$ notations are parameters related to tension and compression stiffness recovery, and determined from equations $(11,12)$

$$
\begin{aligned}
& s_{t}=1-w_{t} r(\sigma) \\
& s_{c}=1-w_{c}(1-r(\sigma))
\end{aligned}
$$

The parameters $w_{c}$ and $w_{t}$ are weight factors for compression and tension stiffness recovery, respectively. $r(\sigma)$ is considers as direction weight designated by the principal stress.

$$
\begin{gathered}
\epsilon_{v}^{p l}=\frac{1}{\mu}\left(1-\epsilon^{p l}-\epsilon_{v}^{p l}\right) \\
d_{v}=\frac{1}{\mu}\left(d-d_{v}\right) \\
\sigma=\left(1-d_{v}\right) E_{\circ}:\left(\epsilon-\epsilon_{v}^{p l}\right)
\end{gathered}
$$




\subsection{Prediction of concrete response}

There are two parameters must be input for any elstic phase simulated materials are; poissons' ratio and modulus of elasticity. For normal concrete material, poissons' ratio ranges between 0.18-0.2. the modulus of elasticity for concrete is directly affected by the compressive strength, and there many relations to predict such parameters

EURO CODE: $\left.E \mathrm{~cm}=22000 \times(0.1 * f \mathrm{~cm})^{\wedge} 0.3\right)$

Where:

$E \mathrm{~cm}$ : modulus of elasticity in MPa

$f_{c m}$ : concrete compressive strength, MPa.

For poissons' ratio parameter, according to FIB model code, ranges between 0.1-0.2 for ranges of stresses between $0.5 \mathrm{fck}$ and fclk, and shall be taken as 0 for cracked section.

\subsubsection{Prediction of concrete nonlinear compressive and tensile behavior}

The FIB90 modal code [3] suggested the relation between compressive stress and strain $\boldsymbol{\sigma}_{\mathbf{c}}$ and $\boldsymbol{\varepsilon}_{\mathbf{c}}$, as shown in Figure.1. for short-term uniaxial loading the comcrete will behave according to the following model:

$$
\begin{aligned}
& \sigma_{c}=f_{\mathrm{cm}} \frac{k \mathrm{\eta}-\mathrm{\eta}^{2}}{1+(k-2) \eta} \\
& \mathrm{k}=1.05 \mathrm{E}_{\mathrm{cm}}\left|\varepsilon_{\mathrm{cl}}\right| / \mathrm{f}_{\mathrm{cm}} \\
& \left.\mathrm{E}_{\mathrm{cm}}=22000 \times(0.1 * \mathrm{fcm})^{\wedge} 0.3\right) \\
& \varepsilon_{\mathrm{c} 1}=0.0014 \times\left(2-\mathrm{e}^{(-0.024 \times \mathrm{fcm})}-\mathrm{e}^{(-0.14 \mathrm{fcm})}\right) \\
& \mathrm{\eta}=\varepsilon_{\mathrm{c}} / \varepsilon_{\mathrm{c} 1} \\
& \varepsilon_{\mathrm{cu}}=0.004-0.0011 \times\left(1-\mathrm{e}^{(-0.0125 * \mathrm{~B} 1)}\right)
\end{aligned}
$$

Where:

$\sigma_{\mathrm{c}}:$ Compressive stress in the concrete;

$k$ : plastic Coefficient;

$\varepsilon_{\mathrm{c}}:$ Compressive strain in the concrete;

$\varepsilon_{\mathrm{c} 1}$ : Compressive strain in the concrete at the peak stress $f_{\mathrm{c} \text {; }}$

$\varepsilon_{c u}$ : Ultimate compressive strain in the concrete.

The Eurocode 2 specifies the modulus of elasticity for concrete to be secant in a range of $0-0.4 \mathrm{fcm}$. Since the basic definition of the material already covers the shear modulus and the longitudinal modulus of concrete, at this stage it is good to assume such an inelastic phase threshold that the initial value of Young's modulus and the secant value determined according to the standard will be convergent. In most numerical analyses, it is rather not the initial behavior of the material, but the stage in which it reaches its yield strength, which investigated. So according to Eurocode, the yield stress start at $0.4 \mathrm{fcm}$

The Two variables must enter to CDP in compression behavior are $\boldsymbol{\sigma}_{\mathbf{c}}$ (start from yield value) and inelastic strain $\left(\widetilde{\varepsilon}_{c}^{i n}\right)$.

$$
\begin{gathered}
\tilde{\varepsilon}_{c}^{i n}=\varepsilon_{\mathrm{c}}-\varepsilon_{c}^{e l} \\
\varepsilon_{c}^{e l}=\frac{\sigma_{c}}{E_{c m}}
\end{gathered}
$$

The degradation of the elastic stiffness is characterized by two damage variables, $d t$ and $d c$, which are assumed to be functions of the plastic strains, temperature, and field variables. Damage, $d t$ and/or $d c$, can be specified in tabular form. (If damage is not specified, the model behaves as a plasticity model; consequently, $\left.\left(\varepsilon_{t}^{p l}=\varepsilon_{t}^{c k}, \varepsilon_{c}^{p l}=\varepsilon_{c}^{i n}\right)\right)$. 
The evolution law $d c-\varepsilon_{c}^{\text {inel }}$ was specified to consider the concrete compression damage after the concrete reaches its peak stress, where $d c$ and $\varepsilon_{c}^{\text {inel }}$ are the compressive damage parameter and compressive inelastic strain, respectively. The expression for $d c$ is given by equation below:

$$
\mathrm{d}_{\mathrm{c}}=1-\frac{\sigma_{\mathrm{c}}}{\mathrm{f}_{\mathrm{cm}}}
$$

The tensile strength of concrete under uniaxial stress is seldom determined through a direct tension test because of the difficulties involved in its execution and the large scatter of the results. Indirect methods, such as sample splitting or beam bending, tend to be used.

$$
\begin{gathered}
\mathrm{f}_{\mathrm{ctm}}=0.3 *\left(\mathrm{f}_{\mathrm{ck}}\right)^{2 / 3} \text { for concrete class }<=50 / 60 \\
\mathrm{f}_{\mathrm{ctm}}=2.12 * \operatorname{Ln}\left(1+\frac{\mathrm{f}_{\mathrm{cm}}}{10}\right) \text { for concrete class }>50 / 60
\end{gathered}
$$

The term cracking strain $\tilde{\varepsilon}_{t}^{\text {in }}$ is used in CDP model numerical analyses. The aim is to take into account the phenomenon called tension stiffening. Concrete under tension is not regarded as a brittle-elastic body and such phenomena as aggregate interlocking. In a crack and concrete-to-steel adhesion between cracks are taken into account. This assumption is valid when the pattern of cracks is fuzzy. Then stress in the tensioned zone does not decrease sharply but gradually. The strain after cracking is defined as the difference between the total strain and the elastic strain for the undamaged material:

$$
\begin{array}{r}
\tilde{\varepsilon}_{\mathrm{t}}^{\text {in }}=\varepsilon_{\mathrm{t}}-\varepsilon_{\mathrm{t}}^{\mathrm{el}} \\
\varepsilon_{\mathrm{t}}^{\mathrm{el}}=\frac{\sigma_{\mathrm{t}}}{\mathrm{E}_{\mathrm{c}}} \\
\text { Where: } \mathrm{E}_{\mathrm{c}}=\mathrm{E}_{\mathrm{cm}}
\end{array}
$$

The proper relation was proposed by, among others, Wang and Hsu:

$$
\begin{aligned}
\sigma_{\mathrm{t}} & =\mathrm{f}_{\mathrm{cm}}\left(\frac{\varepsilon_{\mathrm{cr}}}{\varepsilon_{\mathrm{t}}}\right) \\
\text { Where } \varepsilon_{\mathrm{cr}} & =\frac{\mathrm{f}_{\mathrm{ctm}}}{\mathrm{E}_{\mathrm{c}}}
\end{aligned}
$$

Similarly, the evolution law $d_{t}-\tilde{\varepsilon}_{t}^{\text {in }}$ was specified to capture the concrete tensile damage after the concrete reaches its tensile strength. where $d_{t}$ and $\tilde{\varepsilon}_{t}^{\text {in }}$ are the tensile damage parameter and cracking strain of concrete, respectively. $\tilde{\varepsilon}_{t}^{\text {in }}$ is calculated as the total strain minus the elastic strain corresponding to the undamaged material. $d_{t}$ is determined by the following equation:

$$
\mathrm{d}_{\mathrm{t}}=1-\frac{\sigma_{\mathrm{t}}}{\mathrm{f}_{\mathrm{ctm}}}
$$

\subsubsection{Modelling concrete brittlness behaviour}

Concrete brittile behavior is often characterized by stress crack relationship. The govern equation of this relation can be linear, bilinear, or expentional behavior. The researchers were defined this type of resistance as fracture energy. the FIB CEB 2010 [3] has defined the fracture energy as the energy required to propagate a tensile crack of unit area, it is necessary parameter for brittile materilas, and can be determined using the following equations:

Where:

$$
G_{F}=G_{F 0} \cdot\left(1-0.77 \cdot \frac{f_{c m o}}{f_{c m}}\right)
$$

$G_{F}$ is the base value of fracture energy, N/mm

$G_{F 0}$ : is the base fracture energy, and equal to $0.18 \mathrm{~N} / \mathrm{mm}$ 
$f_{\text {cmo }}: 10 \mathrm{MPa}$

$f_{c m}$ : concrete compressive strength, $\mathrm{MPa}$

It worth to be mensioned that the code identified the pervious equation as it not suitable for very low strength concrete (C15 or below).

\subsection{Codes models for concrete punching shear resistance strength}

The following equations are the punching shear resistance of concrete adopted by virous codes and standards, with out reinforcement. It should be noted that these equations have modified to be without shear reduction factor.

Where:

$$
\begin{gathered}
\text { ACI-318 Code [1]: } V_{C}=0.33 \sqrt{f_{c}} \cdot b \cdot d \\
\text { CSA 23.3 Code [17]: } V_{C}=0.38 \sqrt{f_{c}} \cdot b \cdot d \\
\text { EC2 Code [18]: } V_{C}=0.18 \cdot k\left(100 \cdot \rho_{t} \cdot f_{c}\right)^{\frac{1}{3}} b \cdot d \\
\text { BS } 8110 \text { Code [19] }: V_{C}=0.27 \cdot k\left(100 \cdot \rho_{t}\right)^{\frac{1}{3}} \cdot f_{c}^{\frac{1}{3}} \cdot b \cdot d \\
\text { CEB-FIB MC } 90 \text { [3]: } V_{C}=0.18 \cdot k \cdot f_{c}^{\frac{1}{3}} \cdot \sqrt{100 \rho_{t}} \cdot b \cdot d
\end{gathered}
$$

$V_{C}$ : is punching shear resistance of concrete in $\mathrm{MPa}$;

$f_{c}$ : is concrete compressive strength in $\mathrm{MPa}$;

$\rho_{t}$ : flexural reinforcement ratio for the slab in tension zone;

$d$ : effective slab depth, mm;

$b_{0}$ : is the parameter of cone failure, $\mathrm{mm}$;

$b$ : parameter of punching cone failure, $\mathrm{mm}$;

$K($ EC2 and CEB-FIB MC90 $)=1+\sqrt{200 / d}<2, d$ in $\mathrm{mm}$;

$K(\mathrm{BS} 8110)=\sqrt[4]{400 / d}, d$ in $\mathrm{mm} ;$

\section{Validation of punching shear resistance equations for concrete}

\subsection{Introduction}

State the objectives of the work and provide an adequate background, avoiding a detailed literature survey or a summary of the results.

\subsection{Validity models in Abaqus}

For the first model (model A), the dimensions and properties adopted can be seen in Figure (3), and Table (1), respectively. The concrete flat slab part, a 3D deformable element, an 8-node linear brick, reduced integration, hourglass control (C3D8R), with dimensions $40 \mathrm{~mm}$, and total number of elements 6375 (including column neck), to reduce shear locking effect [20]. while for steel reinforcement, a wire element 2-node linear 3-D truss (T3D2) embedded in the concrete element to simulate full bond [21]. Figure (4) illustrates the FEA model.

The interaction between the supports plates and the concrete is normal hard contact in addition to tangential contact with 0.2 friction coefficient. The streel reinforcement was inserted inside the concrete as embedded region to simulate full interaction bond between the steel bars and the concrete. A rigid body constrain was assigned to the two supports plates to reduce computational time and neglect stresses state in them. A quasi static load was used for the simulation, and a continuous displacement has been applied to the top of the column head till failure.

For the second validated model (model B), two types of flat slab were modeled (model B1 and B2), unreinforced flat slab (model B1) with dimensions 1800x1800x120 mm for length, width and thickness, 
respectively. While the other model (model B2) included steel stud's rebar as punching shear reinforcement, with the same slab dimensions [22], as presented in Figure (6).

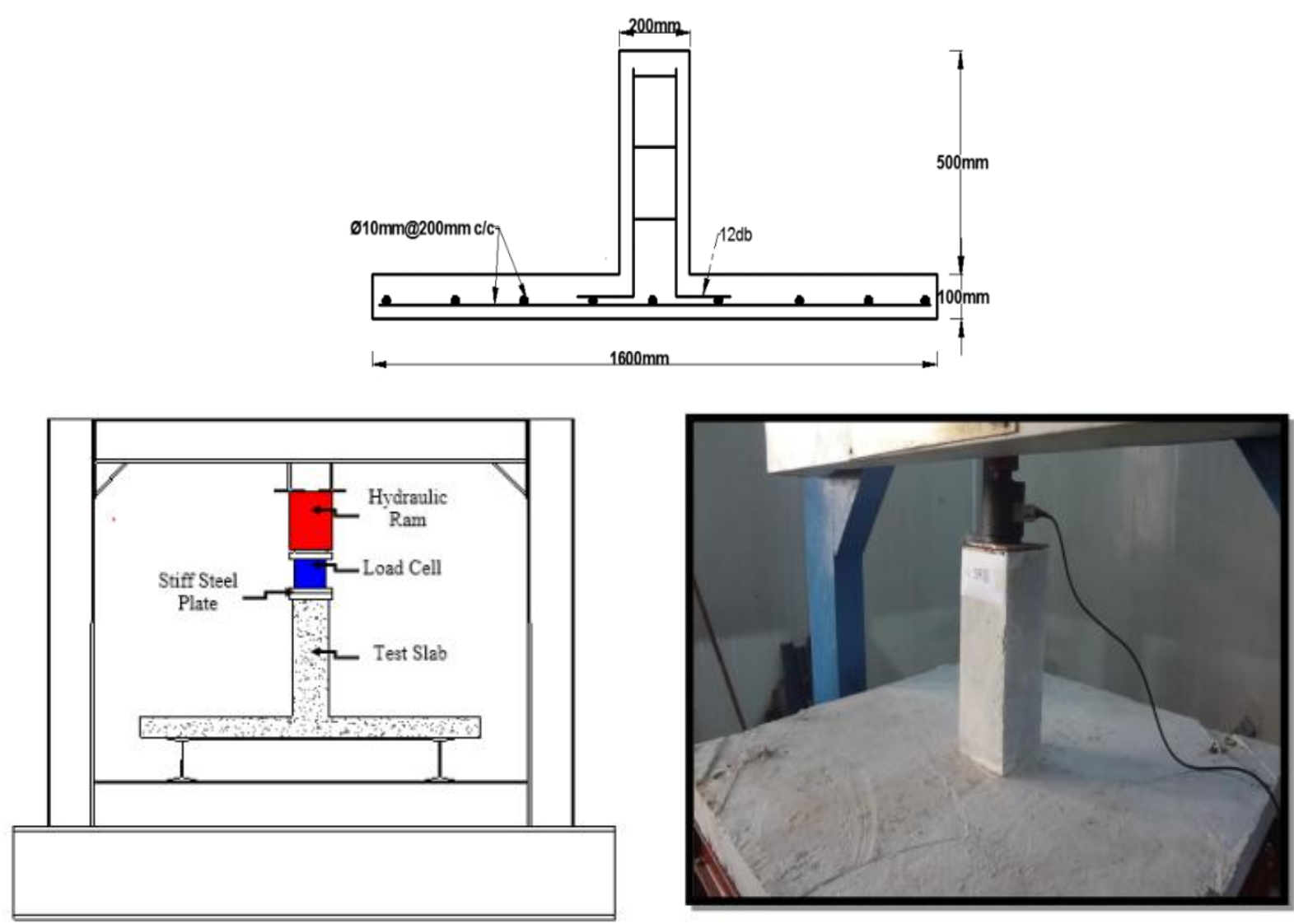

Figure 3. Experimental work details and speciemens preparation [8].
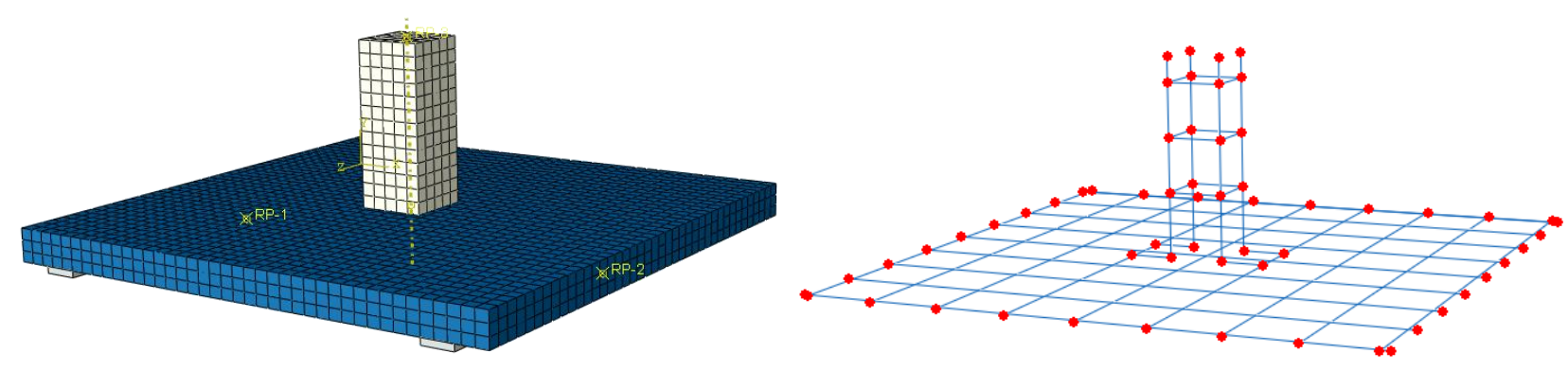

Figure 4. FEA simulation of the falt slab model (left) and the steel reinforcement bar (right)

Table 1. selected CDP material parameter for $25 \mathrm{MPa}$ concrete compressive strength.

\begin{tabular}{c|c}
\hline Parameter & Selected value \\
\hline Material model & CDP model \\
\hline E, MPa & 28000 \\
\hline Possions ratio & 0.18 \\
\hline Dilation angel & 36 \\
\hline Ecc & 0.1 \\
\hline Fb0/fc0 & $1.16[20]$ \\
\hline $\mathrm{K}$ & $0.667[20]$
\end{tabular}




\begin{tabular}{c|c} 
Parameter & Selected value \\
\hline Viscosity parameter & $0.001[23]$ \\
\hline Fracture energy, N/mm & 0.0474
\end{tabular}

After illustration of the govern equation that listened in EC2 and FIB90 codes for concrete strength properties curves (tensile and compressive stress corresponding to cracking strain and inelastic strain, respectively), Figure (5) present material characteristics of concrete behavior under uniaxial load for concrete compressive strength of $25 \mathrm{MPa}$. It should be noted that maximum inelastic strain that the code permits maximum inelastic strain according to the compressive strength class (for $\mathrm{C} 25, \varepsilon \mathrm{c} 1=2.2 \%$ ).
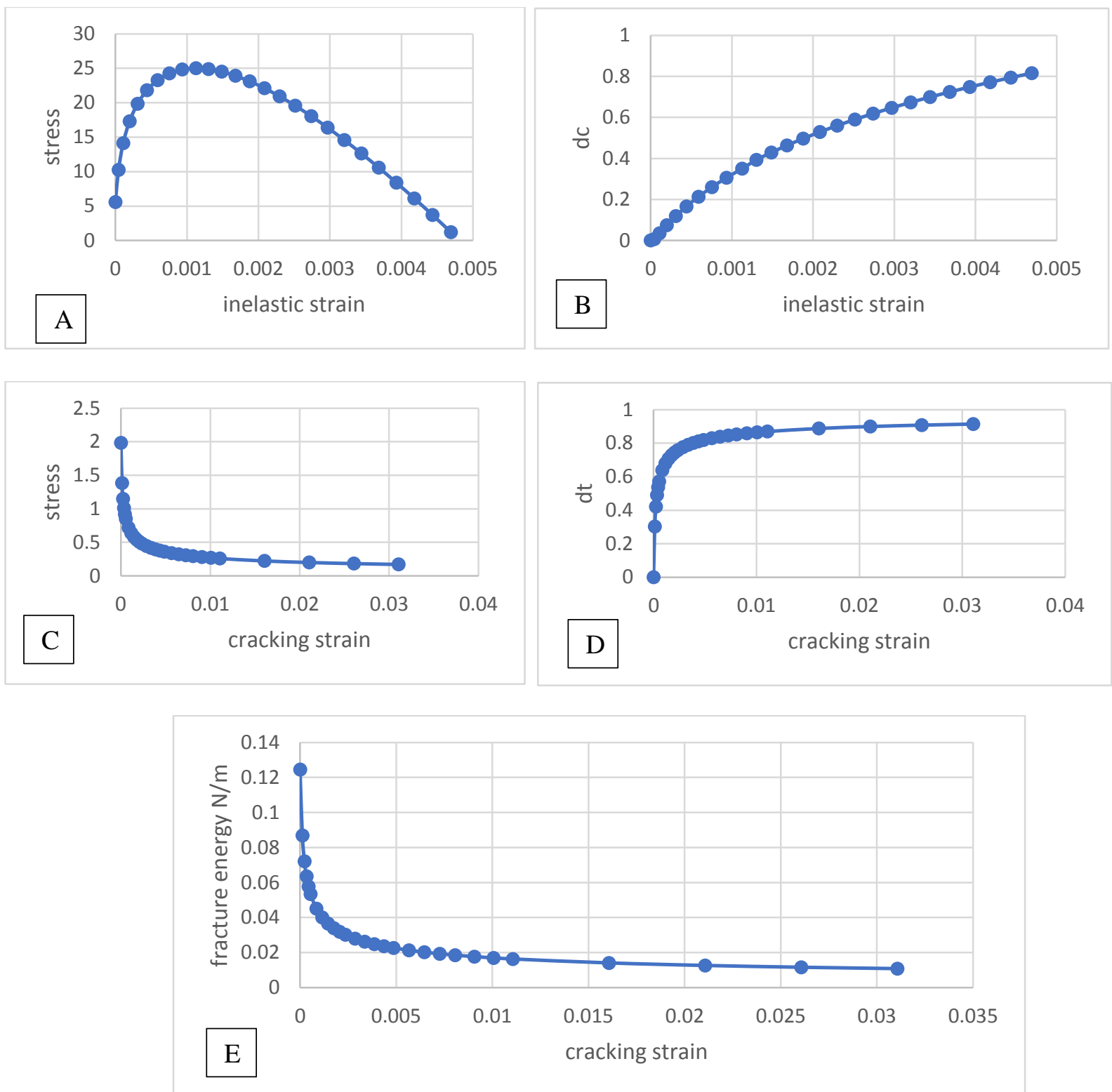

Figure 5. concrete material properties results for compressive strength $25 \mathrm{Mpa}$ (A,B,C,D, AND E)

The reinforced steel bars properties as presented in Table (2). It should be noted that the nonlinear part of stress strain relation was simplified to idealized linear relation. 
Table 2. steel reinfrocement properties for model A

\begin{tabular}{c|c}
\hline parameter & Selected value \\
\hline Model type & Idealized stress strain behaviour \\
\hline E, MPa & 200000 \\
\hline Possons ratio & 0.3 \\
\hline Yield stress, Fy & 635 \\
\hline failure stress, Fu & 713 \\
\hline
\end{tabular}

\subsection{Validity of second experimental adopted specimens for reinforced and unreinforced punching shear flat slab (B1 and B2)}

In general, the same method for modelling the first model were followed in term of, applied load, steel and concrete interaction and type of elements. The adopted second model having flat slab dimensions of 1800x1800x120 m, column dimensions 150X150 mm, other details as clarified in Figure (6).

For FEA unreinforced model elements details, total number of nodes are 25187 , total number of elements are 19070, there are 1188 linear line elements of type T3D2, and 17882 linear hexahedral elements of type C3D8R. For FEA reinforced model elements details, the total number of nodes are 25934, total number of elements are 19754, there are 1388 linear line elements of type T3D2, and 18366 linear hexahedral elements of type C3D8R. Figure (7) illustrates the FEA model.

Concrete material properties are the same as the first validated model in Table (1), except concrete compressive strength and stress strain behavior properties, which have adopted from the results in Figure (8). Steel material properties for bars and studs that used in simulation are presented in Table (3)

Table 3. Steel and studs reinfrocement properties for the second model (model B1andB2)

\begin{tabular}{c|c}
\hline parameter & Selected value \\
\hline Model type & Idealized stress strain behaviour \\
\hline E, MPa & 200000 \\
\hline Possons ratio & 0.3 \\
\hline Yield stress, Fy & 455 \\
\hline Fracture stress, Fu & 650 \\
\hline Fy studs, MPa & 381 \\
\hline
\end{tabular}
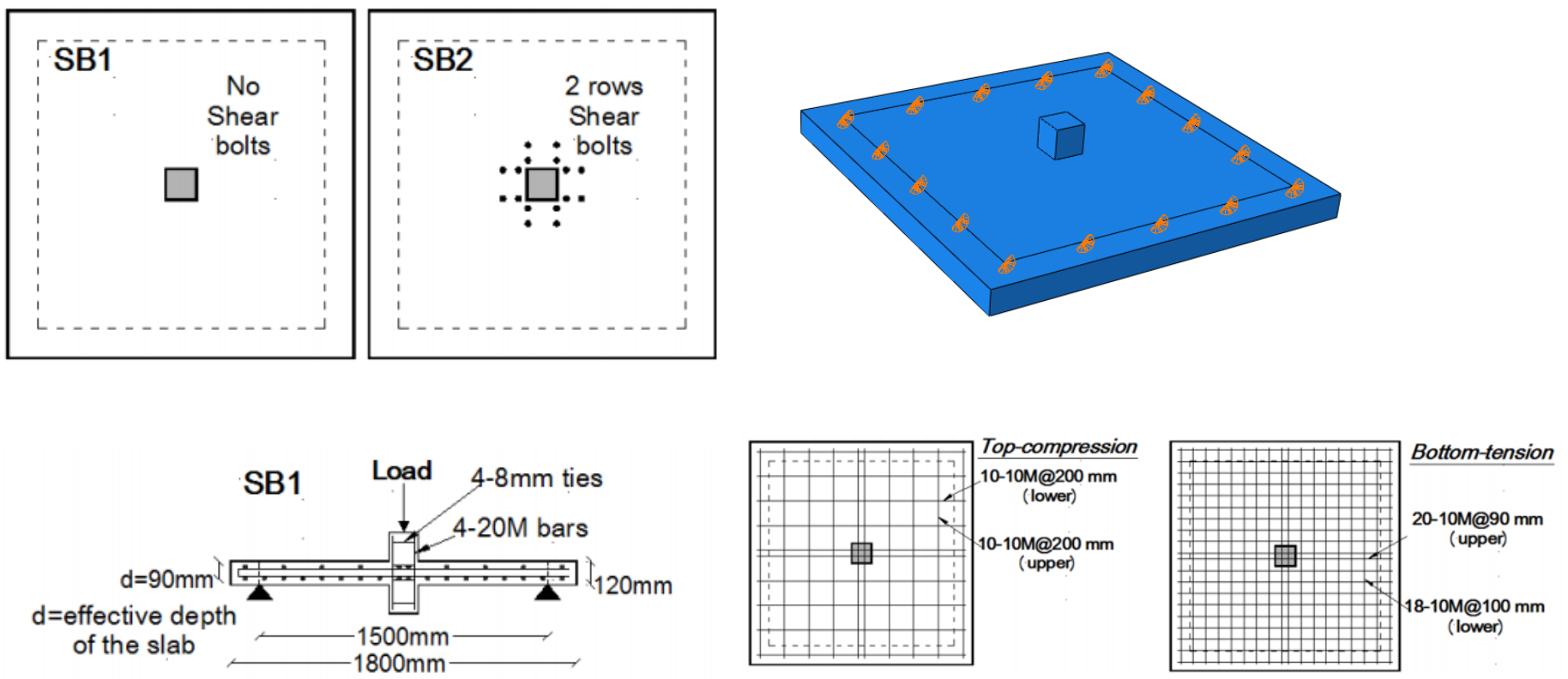

Figure 6: The adopted experimental work details for models B1 and B2 [22] 


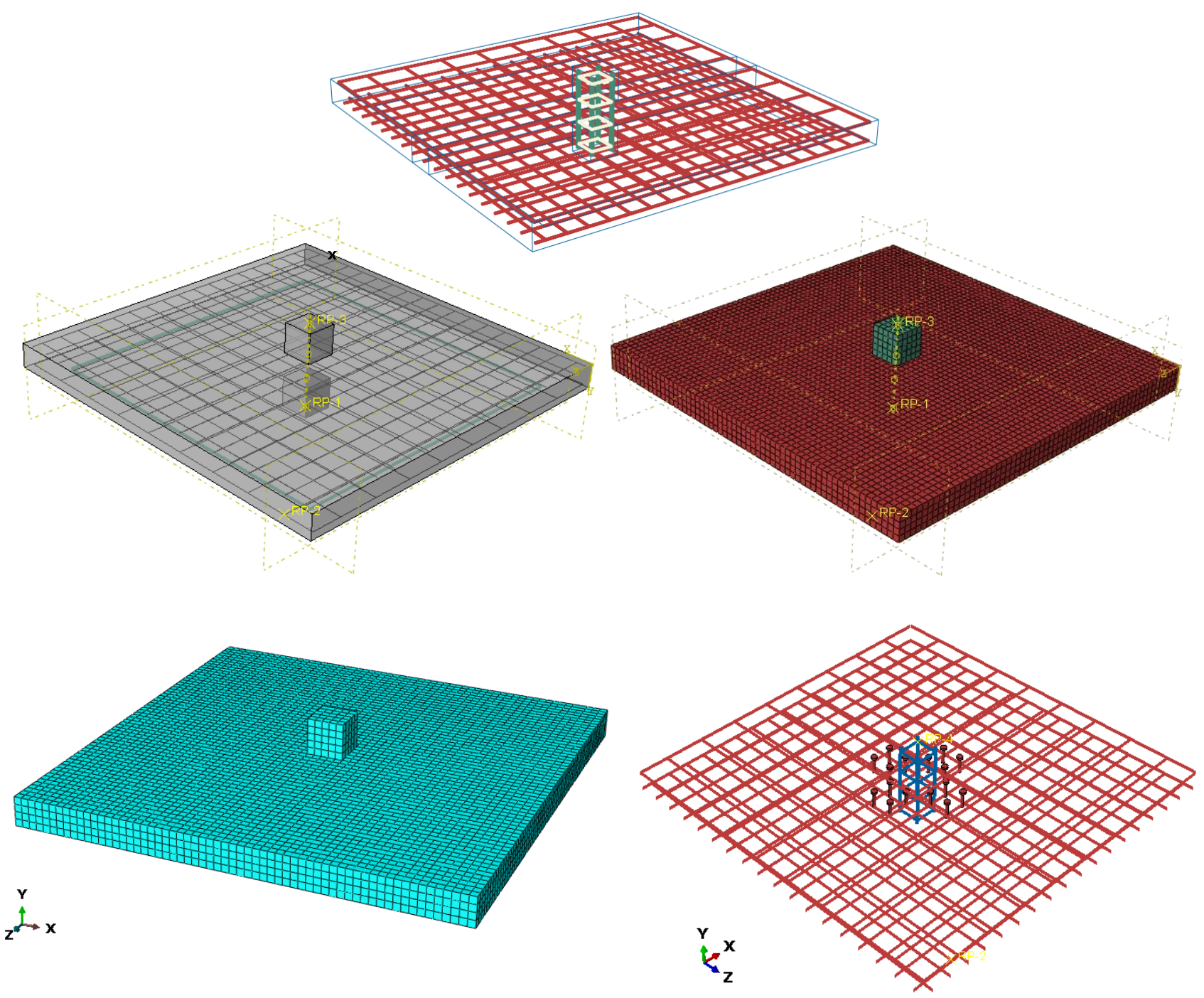

Figure 7. The simulated model (B) in Abaqus

After illustration of the govern equation that listened in EC2 and FIB90 codes for concrete strength properties curves (tensile and compressive stress corresponding to cracking strain and inelastic strain, respectively), Figure (8) presents material characteristics of concrete behavior under uniaxial load for concrete compressive strength of $41 \mathrm{MPa}$. It should be noted that maximum inelastic strain that the code permits maximum inelastic strain according to the compressive strength class.
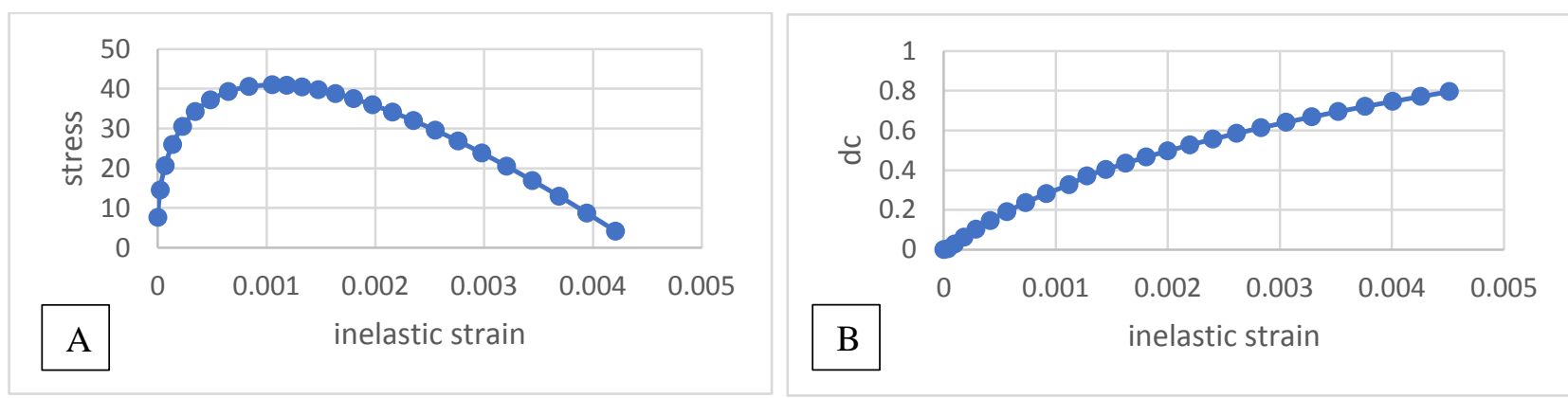

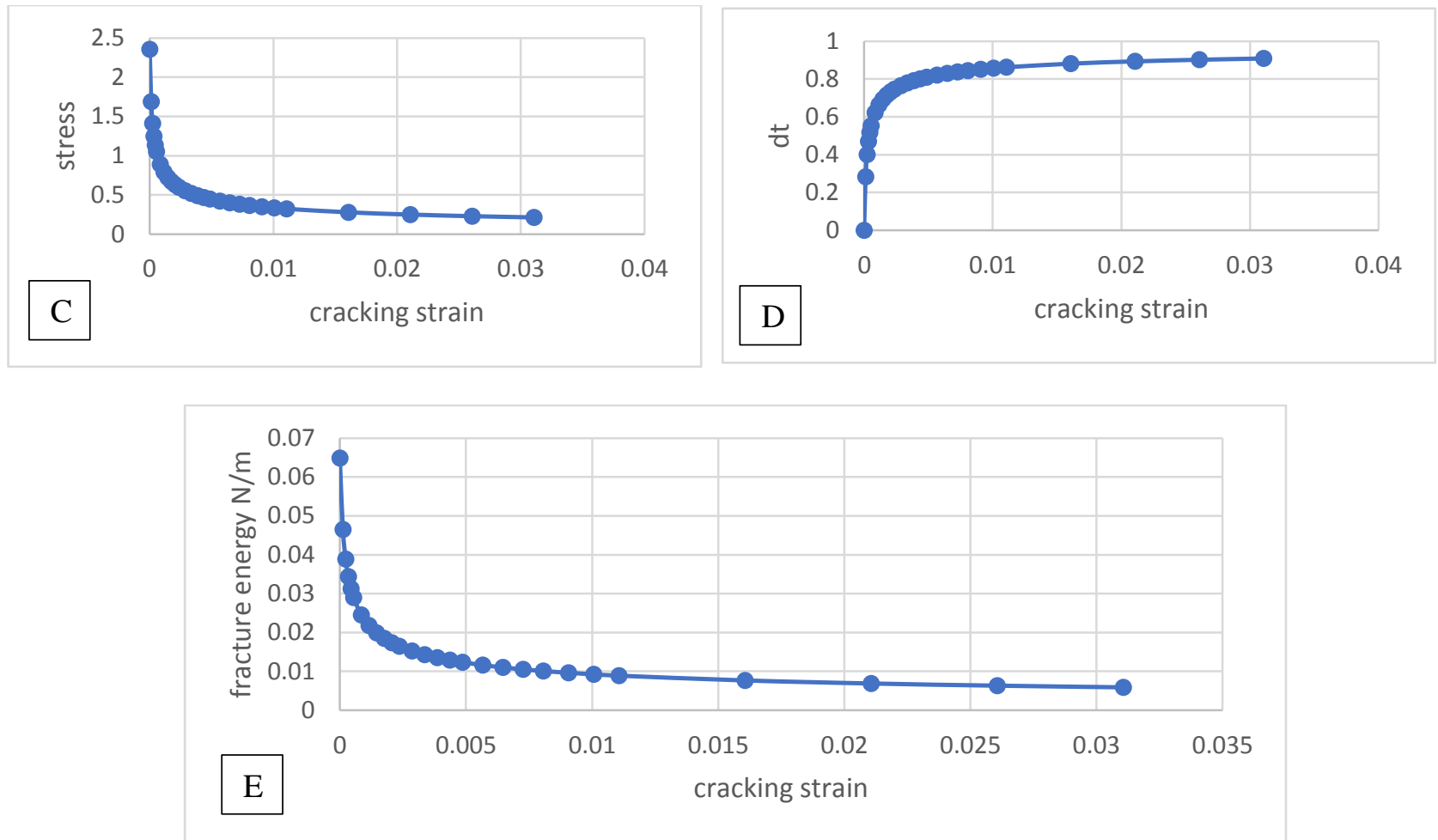

Figure 8. concrete material properties results for compressive strength $41 \mathrm{Mpa}$ (A,B,C,D, AND E)

\section{4 validity results of modal $\mathrm{A}$}

After generating concrete material properties and building the FEA model, results of the flat slab concrete resistance to punching force against midspan vertical displacement was compared with the adopted experimental curve, as can be seen in Figure (9). For the same Figure it can be observed that both of numerical model behavior and the experimental model matches for both aspects, maximum force and maximum displacement. The numerical modal reflected max shear force resistance of $119 \mathrm{KN}$ with deflection at slab mid span of $17.36 \mathrm{~mm}$, which is very similar to the experimental results $(128 \mathrm{KN}$ punching shear and $16.5 \mathrm{~mm}$ slab mid span deflection). It should be noted that the linear part of both curves are matches, then the FEA model reflected higher resistance up to $13 \mathrm{~mm}$ displacement, then the curve started to decrease below the experimental modal curve up to the maximum punching force.

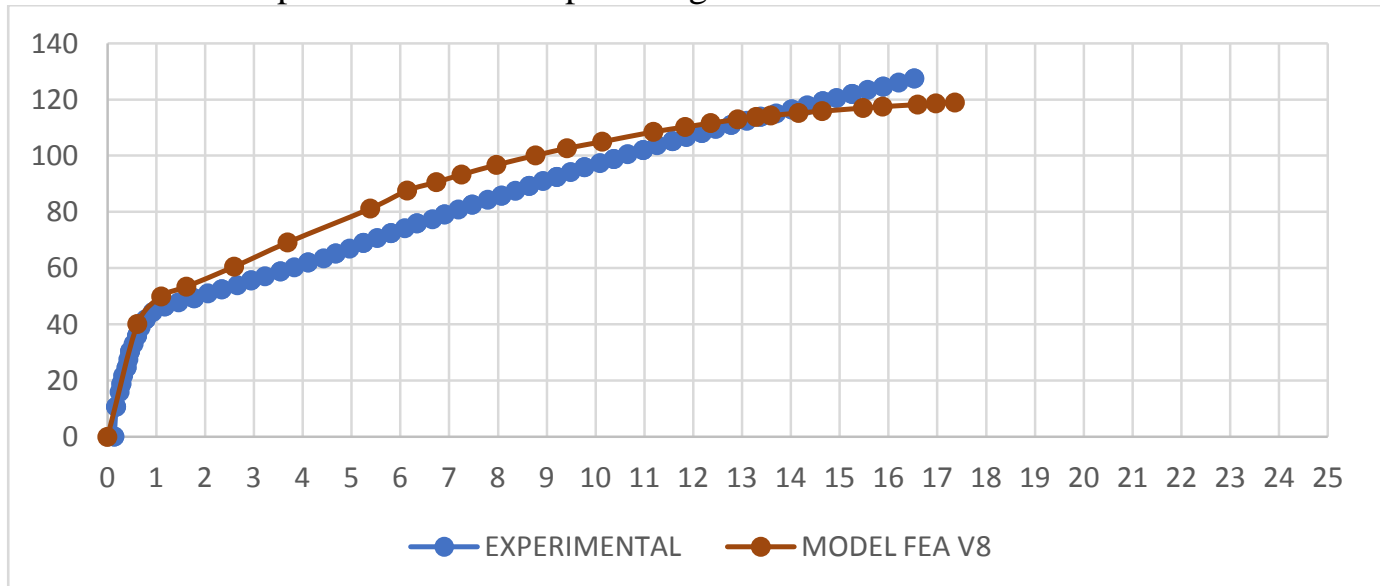

Figure 9. Validation the punching shear force vs vertical midspan displacement curves of the simulated mode (model A). 
From other side, and be means of visual comparison methodology, it can be observed that the FEA modal in term of tension damage pattern has reflected the experimental pattern perfectly, as can be seen in Figure (10). The plastic stain and von mises stresses criteria for steel bar reinforcement and flat slab are illustrated in Figure (11). The Figure illustrates that maximum stress were consternated at the mid of slab, under column head, then begin to decrease far from the mid until the supports.
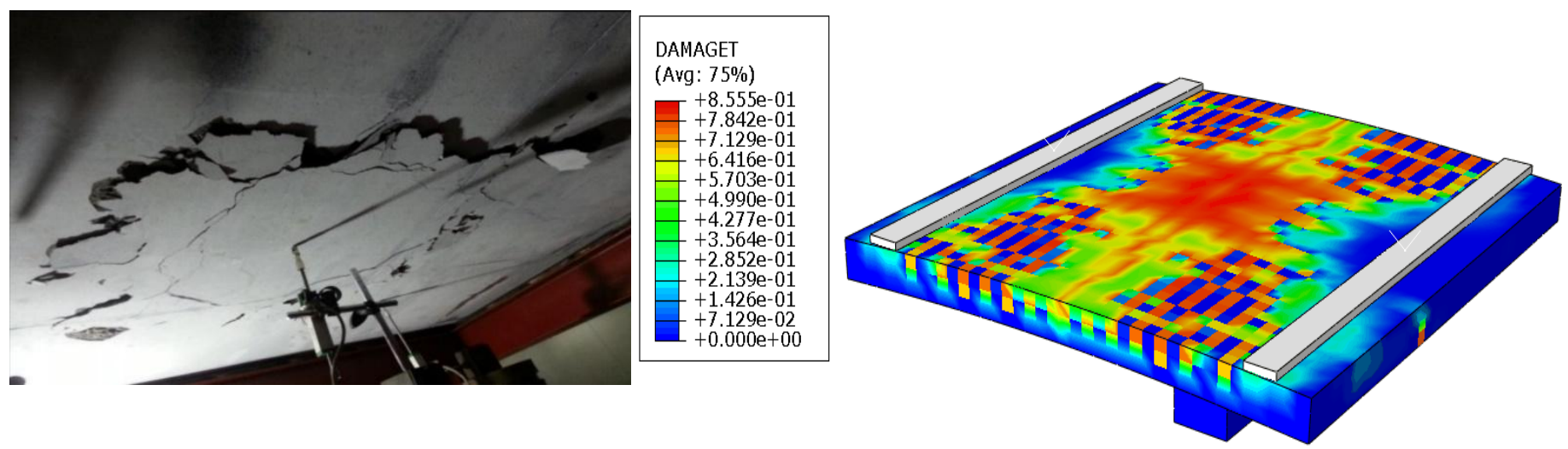

Figure 10. Comparision between the experimental specimen's failure and the FEA modes (modelA)

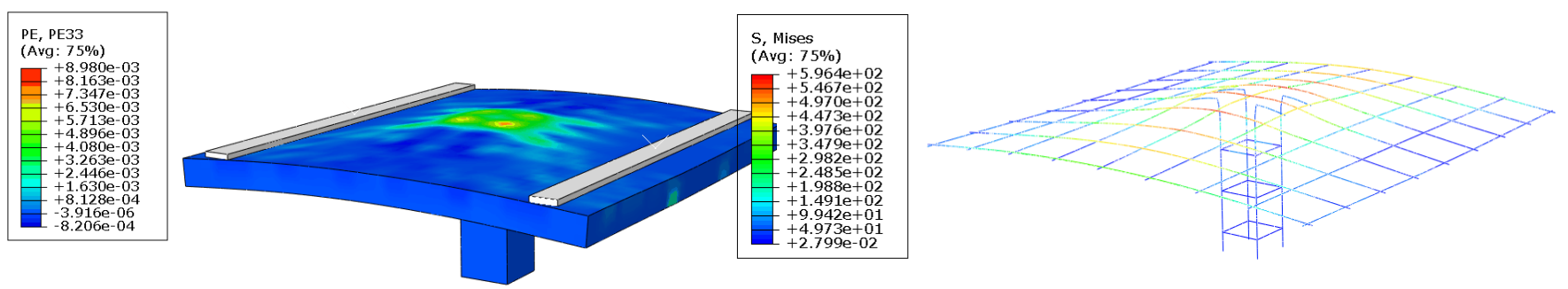

$t^{2} x$

Figure 11. Platic strain and von mises stress for the concrete falt slab and reinforcement for model A,

respectively.

\subsection{Validation results comparision with various codes models}

Table (4) and Figure (12) represent a wide range of comparison of the experimental and simulated FEA results of punching shear resistance with the models that adopted in the standards (ACI-318, BS8110, EC2, CEB-FIB MC90). The parameters used in calculation are for model 1 (modelA). It should be noted that all values in the Table (4) are obtained in the absence of shear strength reduction factor. ACI, CSA take critical section at d/2, EC2 and CEB-FIB 90 take critical section at 2d, BS code takes critical section at $1.5 \mathrm{~d}$, all from face of support.

Table 4. General comparision between the experimental and FEA results with codes models

\begin{tabular}{c|c}
\hline code & Punching shear value, KN \\
\hline Experimental & 128 \\
\hline FEA Simulation in Abaqus & 119 \\
\hline ACI-318 2014 & 142.56 \\
\hline CEB-FIB MC1990 & 133.8
\end{tabular}




\begin{tabular}{c|c}
\hline code & Punching shear value, KN \\
\hline EC2 2010 & 141 \\
\hline BS-8110 1990 & 126.72 \\
\hline CSA A23.3-2010 & 164 \\
\hline
\end{tabular}

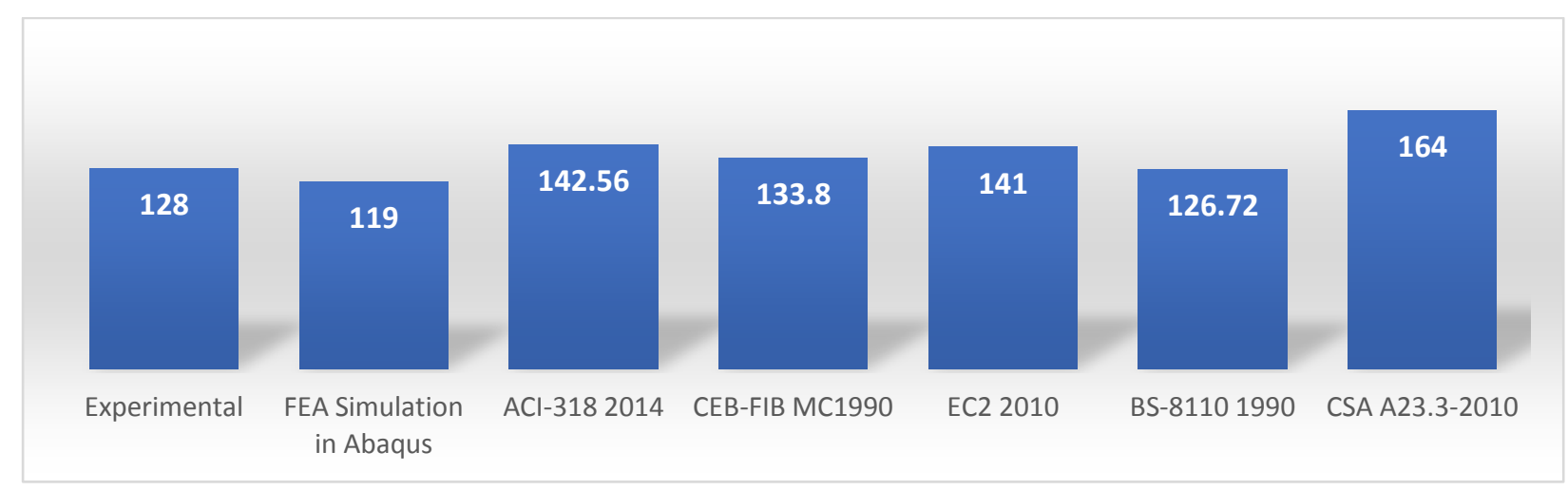

Figure 12. Punching shear resistance comparision for the FEA result of model A with different codes models

results

\subsection{Results of the validity of the modal B1 and B2}

For the second FEA model (type B), the unreinforced type (B1), the FEA modal curves showed higher resistance to punching shear resistance when compared to the adopted experimental modal curve, as can be seen in Figure (13). Also, it should be noted that the FEA modal curve behaved exactly like the experimental one. The numerical modal reflected max shear force resistance of $292 \mathrm{KN}$ with deflection at slab mid span of $10.5 \mathrm{~mm}$, which is comparable to the experimental results $(250 \mathrm{KN}$ punching shear and $12.24 \mathrm{~mm}$ slab mid span deflection). It should be noted that the linear part of both curves are matches, then the FEA model curves gave higher resistance than the experimental model.

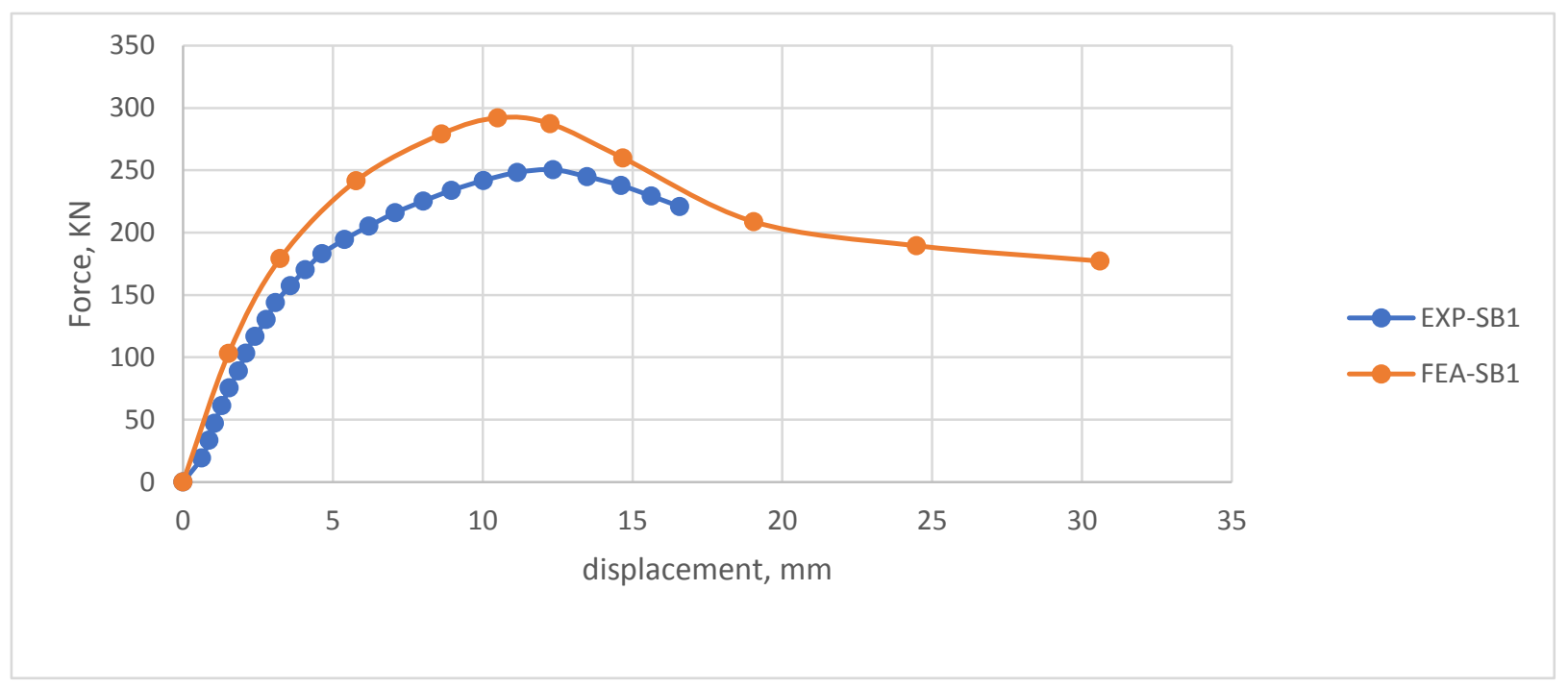

Figure 13.Validation of unreinforced flat slab (model B1) resistance curve with the FEA curve 
While For the model B2, the reinforced model with stud's type, the FEA modal curves showed higher resistance to punching shear resistance when compared to the adopted experimental modal curve. Also, it should be noted that the FEA modal curve behaved linearity and matches the experimental curve, as can be seen in Figure (14). The numerical modal reflected max shear force resistance of $340.7 \mathrm{KN}$ with deflection at slab mid span of $16.3 \mathrm{~mm}$, which is comparable to the experimental results (364 KN punching shear and $14.52 \mathrm{~mm}$ slab mid span deflection).

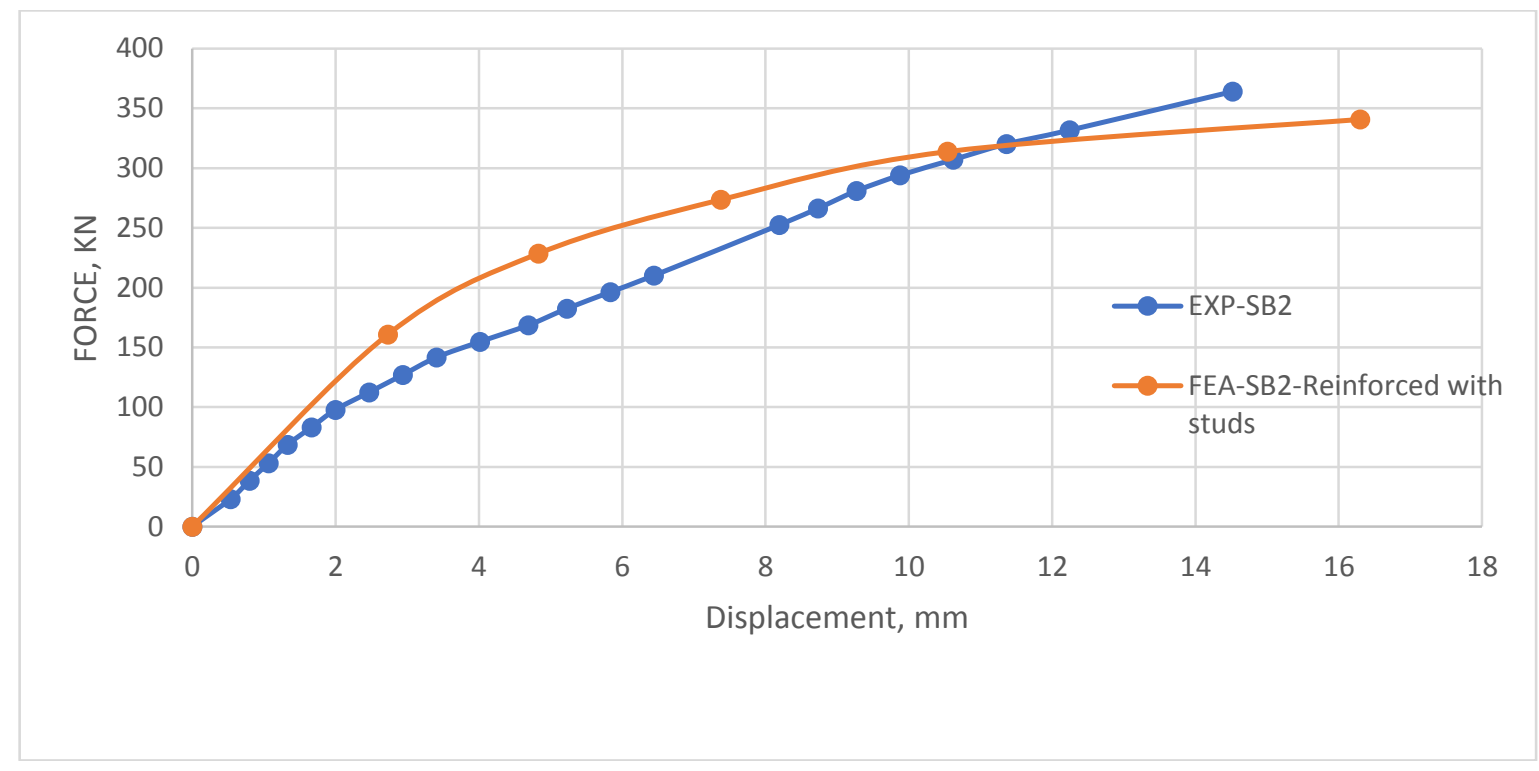

Figure 14. Validation of the reinforced flat slab (model B2) resistance curve with the FEA curve

Figures (15) and (16) illustrates top and perspective views of the FEA failure pattern. It can be observed the inside circle around the column which represents punching shear cone failure. the larger cone diameter means higher punching shear resistance, because of increasing area resistance to punching. Also, it can be observed the stresses intensity near column face is higher than other area.
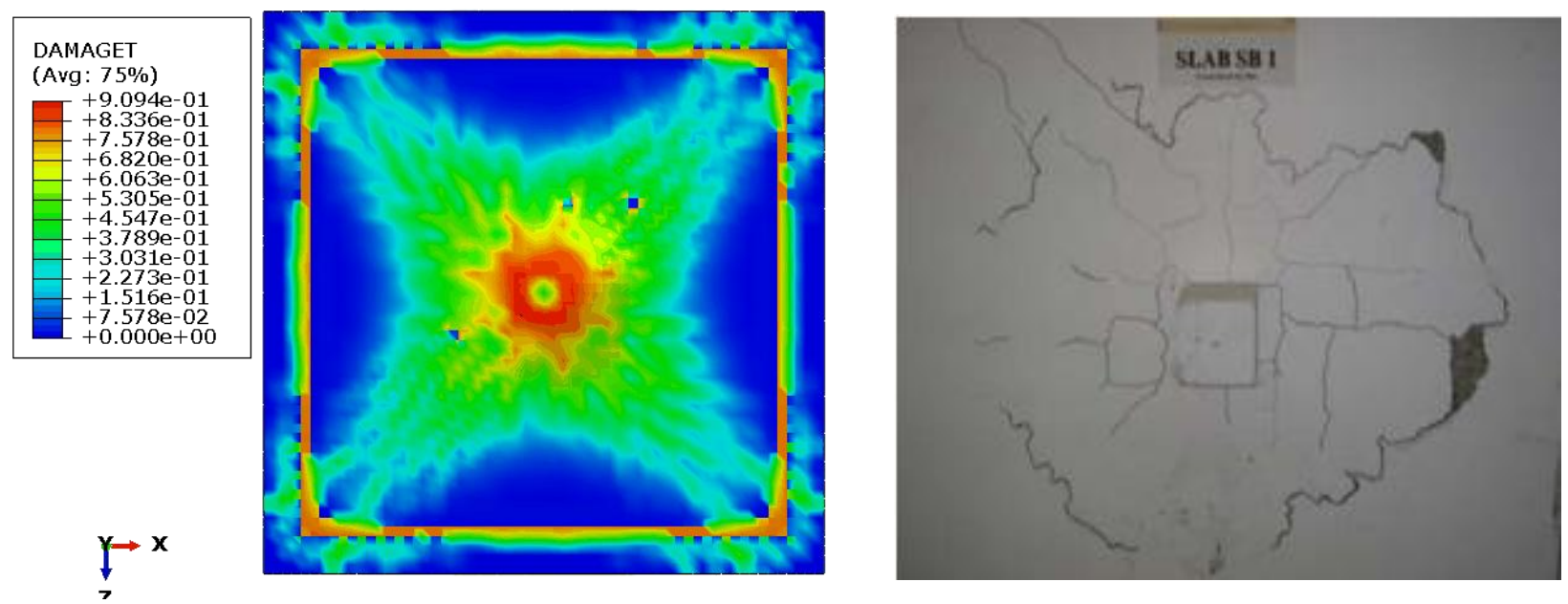

Figure 15. Visual comparsion between the unreinforced flat slab failure and the FEA failure results (model 

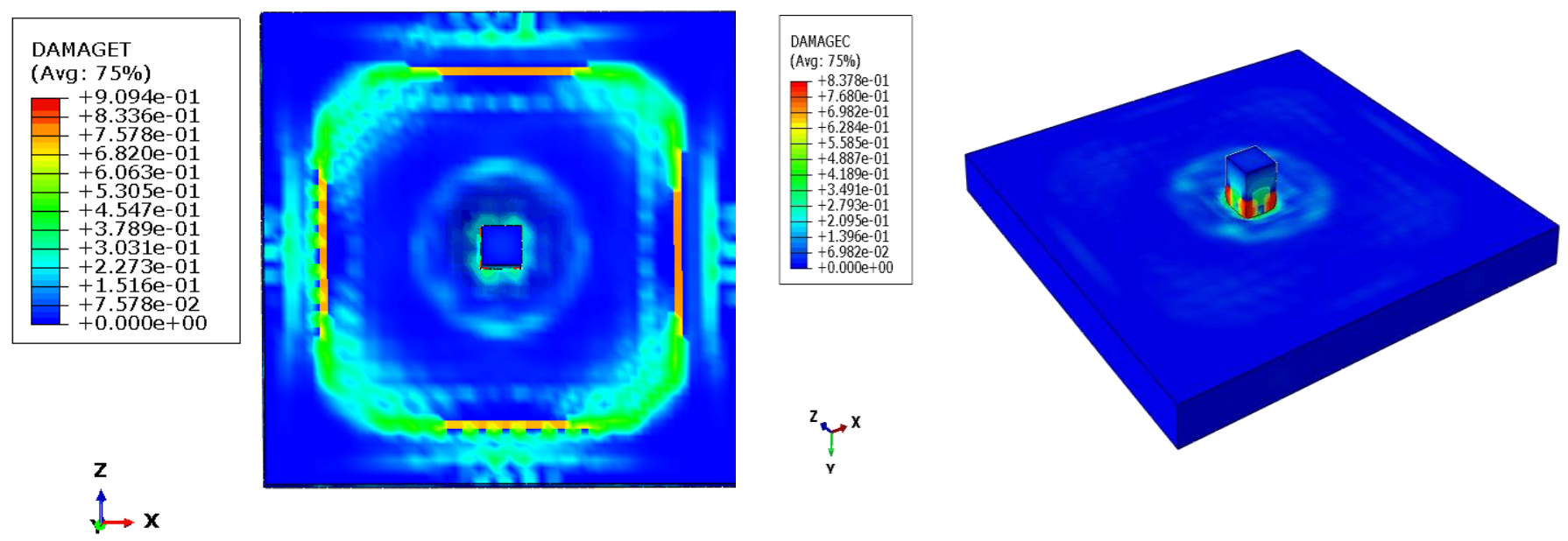

Figure 16. Top and prespective veiws for the tensile cracking damage for the FEA model-B1

\section{Conclusions}

This study included a method for predicting and validating various concrete strength calss behaviour of flat slab structure and comaore the results with an adopted experimental work. Aslo, a comperhansive comparsion was performed with some codes and standards such as ACI-318, BS8110, EC2, and CSA23.3. after presenting and discussing the results, the following conclsion can be drwan:

1- The resulted curves responce models adopted from EC2 and FIB90 modal code for concrete material was abile to perfecly capture the stress strain behaviour for the flat slab structure subjected to punching shear force.

2- The finite element simulatation in term combination of the adopted concrete responce reflected very good results in comparsion with experimental models.

3- All aopted codes models for predicting puncing shear resistance were underestimation when compared with experimental and FEA model.

4- The adopted concrete damaged placiticty model was able to capture concrete responce when the fla slab reinforced with studs.

\section{References}

[1] A. C. I. Committee, Building code requirements for structural concrete : (ACI 318-14) ; and commentary (ACI 318R-14). Farmington Hills, MI : American Concrete Institute, [2014] (C2014, 2014.

[2] B. J. L. B. S. I. BS, "Part 1, Code of practice for design and construction, structural use of concrete," 1997.

[3] C. E. E.-i. D. B. Eton, CEB-FIP Model Code 1990: Design Code. T. Telford, 1993.

[4] D. Faria, H. Biscaia, V. Lúcio, and A. Ramos, "Material and geometrical parameters affecting punching of reinforced concrete flat slabs with orthogonal reinforcement," in fib Symposium, Prague, 2011.

[5] M. Bartolac, D. Damjanović, and I. J. G. Duvnjak, "Punching strength of flat slabs with and without shear reinforcement," vol. 67, no. 08., pp. 771-786, 2015.

[6] N. V. Ramana, K. Gnaneswar, C. Sashidhar, T. N. J. I. J. o. S. Kumar, and A. Technology, "Behavior of High Performance Concrete Two Way Slabs in Punching Shear," vol. 2, no. 3, pp. 122-126, 2012. 
[7] N. A.-A. Alwash, G. M. Habeeb, and H. T. J. J. o. U. o. B. Nhabih, "Experimental and Numerical Investigation on The Punching Behavior of High Strength RC Flat Slab Under Repeated Load," vol. 25, no. 2, pp. 497-494, 2017.

[8] H. K. Ammash and S. S. J. J. o. S. J. U. Kadhim, "Effect of Reinforced Concrete Column Capital on Punching Shear Strength of Flat Slab," vol. 54, no. 5, 2019.

[9] D. Bompa and A. Elghazouli, "Nonlinear numerical simulation of punching shear behaviour of reinforced concrete flat slabs with shear-heads," 2019.

[10] M. Fernández Ruiz and A. J. A. S. J. Muttoni, "Applications of the critical shear crack theory to punching of R/C slabs with transverse reinforcement," vol. 106, no. ARTICLE, pp. 485-494, 2009.

[11] A. Genikomsou and M. Polak, "Finite element analysis of a reinforced concrete slab-column connection using ABAQUS," in Structures Congress 2014, 2014, pp. 813-823.

[12] A. S. Genikomsou and M. A. Polak, "Damaged plasticity modelling of concrete in finite element analysis of reinforced concrete slabs," in 9th International Conference on Fracture Mechanics of Concrete and Concrete Structures University of California, 2016, pp. 22-25.

[13] A. S. Genikomsou and M. A. J. J. o. S. E. Polak, "Finite-element analysis of reinforced concrete slabs with punching shear reinforcement," vol. 142, no. 12, p. 04016129, 2016.

[14] J. Lubliner, J. Oliver, S. Oller, E. J. I. J. o. s. Oñate, and structures, "A plastic-damage model for concrete," vol. 25, no. 3, pp. 299-326, 1989.

[15] J. Lee and G. L. J. J. o. e. m. Fenves, "Plastic-damage model for cyclic loading of concrete structures," vol. 124, no. 8, pp. 892-900, 1998.

[16] W. J. W. T. U. o. W. Bu, "Punching Shear Retrofit Method Using Shear Bolts for Reinforced Concrete Slabs under Seismic Loading/Wensheng Bu," 2008.

[17] A. G. Sherif and W. H. J. C. J. o. C. E. Dilger, "Critical review of the CSA A23. 3-94 punching shear strength provisions for interior columns," vol. 23, no. 5, pp. 998-1011, 1996.

[18] T. J. E. C. f. S. CEN, "EN 1992-1-1: Eurocode 2: Design of Concrete Structures-Part 1-1: General Rules and Rules for Buildings," 2004.

[19] B. S. Institution, Structural Use of Concrete: BS8110:.. Code of practice for design and construction (no. pt. 1). BSI, 1997.

[20] A. U. J. P. U. Manual, "Dassault Systèmes Simulia Corporation," 2010.

[21] A. S. Genikomsou and M. A. J. E. S. Polak, "Finite element analysis of punching shear of concrete slabs using damaged plasticity model in ABAQUS," vol. 98, pp. 38-48, 2015.

[22] B. Adetifa and M.A.Polak, ACI Structural Journal, " Retrofit of Slab Column Interior Connections Using Shear Bolts," vol. 102, no. 2, pp. 268-274, 2005.

[23] J. Lee, G. L. J. E. e. Fenves, and s. dynamics, "A plastic- damage concrete model for earthquake analysis of dams," vol. 27, no. 9, pp. 937-956, 1998. 